\title{
STUDY INTO THE CHANGES IN SOIL ORGANIC MATTER, CAUSED BY LABORATORY SIMULATED FIRES IN FOUR SLOVAK SOILS 1. UV-VIS SPECTRUM ANALYSIS
}

\author{
Maroš SIROTIAK $^{1}$, Alica PASTIEROVÁ ${ }^{1}$, Lenka BLINOVÁ ${ }^{1}$ \\ ${ }^{1}$ Slovak University OF TECHNOLOGY IN BRATISLAVA \\ FACULTY OF MATERIALS SCIENCE AND TECHNOLOGY \\ INSTITUTE OF INTEGRATED SAFETY \\ Ulica JÁNA BotTu 2781/25, 91724 TRNAVA, SLOVAK REPUBLIC \\ e-mail: maros.sirotiak@stuba.sk. alica.pastierova@stuba.sk, lenka.blinova@stuba.sk \\ Received 26 April 2021, Accepted 29 June 2021, Published 20 July 2021
}

\begin{abstract}
The study was focused on describing ultraviolet-visible spectra of the humic substances, humic acids and fulvic acids isolated from four Slovak soils. The samples were heated in a laboratory furnace, to simulate soil behaviour during fires. The absorbances at the wavelengths corresponding to the selected chromophores and specific wavelength for groups of substances were compared. Analysis of the UV-VIS spectra of the extracted humic substances may indicate the directions of interest in the changes in soil organic matter, along with the changes in external conditions, such as natural fires.
\end{abstract}

\section{Keywords}

Fire, Humic substances (HS), Humic acid (HA), Fulvic acid (FA), UV-VIS spectrophotometry

\section{INTRODUCTION}

Fires affect soil properties in many ways. Some changes are associated with overall changes in the ecosystem (e.g., species composition and their abundance in soil biocenosis, soil-plant roots interactions), others with physico-chemical soil characteristics (e.g., moisture, water capacity), while further are related to soil chemical characteristics (changes in soil organic matter, changes to nutrient regimes, increase in biomass content at different stages of thermal alternation, so-called biochars).

The organic portion, which is represented in soil in the range of $2-5 \%$ implies non-living organic matter in various stages of decomposition (about $84 \%$ of soil organic matter) and living organisms (living organisms and the roots take up $16 \%$ of soil organic matter). [1] Soil organic matter (SOM) is one of the most important parameters breakable by fire, which affects movement, respectively, retention of inorganic and organic substances. Their binding to humus is one of the most important reaction, through which are transformed anthropogenic chemicals 
in nature. These interactions strongly depend on the protonation and complexation properties of SOM that are affected in complex ways by the molecular weight of SOM, its concentration and proton/metal cation affinities of the carboxylic, phenolic and other functional groups typical for both, terrestrial and aquatic SOM [2].

\section{Humic substances (HS)}

The soil organic matter can be divided into two groups [1, 2, 3]:

- Non-specific humic substances (also called non-humine substances or primary SOM) comprise about $10-15 \%$ of the SOM, and represent the decomposed or partially decomposed plant residues, organic fertilizers, animals and micro-organisms. This part of the humus contains more biochemical components that can be chemically determined, such as sugars, fats, proteins, amino acids, nucleic acids, etc. The presence of these substances is a prerequisite for the biological activity of the soil, forming energy and nutrient supply of the soil, which is due to the carbon content which serves as an energy source for soil microorganisms. These components are also actively involved in the processes of humification, mineralization and photosynthesis, and are the most important part of biogeochemical processes on Earth. Decomposed remains of plants, animals and organic fertilizers in the soil gradually transform the participation of soil microorganisms.

- Specific humic substances (also called humine substances or secondary SOM) - these, although the soil represents just a few percent, play an important part of humus, which is due to their chemical activity. Specific humic substances are created via chemical and biological degradation of organic materials (in particular devitalized plant material) and synthetic activity of the microorganisms. They represent a complex high-molecular polycyclic compound with a molecular weight in the range of several hundred to tens of thousands of Daltons. The molecular weight of humic acids is affected by the carbon and the oxygen content changes during the conversion of the primary SOM. Their structure is amorphous or colloidal, predominantly aromatic in character, and the nuclei are linked by aliphatic, often cyclic, chains. The functional groups that bind directly to the aromatic or side chain include, for example, the carboxylic, hydroxyl, but also methoxy and carbonyl groups. In the humification process, the $-\mathrm{COOH},-\mathrm{OH}$ and $-\mathrm{C}=\mathrm{O}$ groups increase, but, on the contrary, the content of alcohol and phenolic $-\mathrm{OH}$ groups and $-\mathrm{OCH}_{3}$ groups decreases. In contrast to non-humic substances, they are characterized by their resistance to biological transformation. Humic substances are further classified into humus acids (humic acids; fulvic acids; hymatomelanic acids); salts of humus acids (humates, fulvates), and humus (humus coal).

\section{Humic acids (HA)}

The structure of humic acids is very complex and has not been fully described yet. The basis of some proposed hypotheses about the conformation and structure of humic substances suggests that the predicted structure of these substances is in the form of dimers, trimers, tetramers, and hexamers. The carbon content is about $52-65 \mathrm{wt} . \%$, Oxygen is present in $30-39$ wt. $\%$, hydrogen $2-6$ wt. $\%$ and nitrogen also $2-6$ wt. $\%$. The basis of molecular construction is aromatic nuclei of the phenolic or quinoid types. The presence of functional groups, such as carboxyls having a relatively strong acidic character and phenolic hydroxyl groups having only a weak acidic character, give these compounds an acidic character. Owing to the presence of an aromatic nucleus with aliphatic chains and bonded functional groups, humic acids can bind both, polar and non-polar compounds. Functional groups may be attached to the structure on both, the aromatic nuclei and the side chains. Of all functional groups present 
in humic acids, the most reactive carboxyl groups are present. Besides, the enol, quinone, hydroquinone, ether and alcohol groups are present in the acids. In smaller quantities, nitrogen, sulphur, and phosphorus functional groups may also be present [1, 4].

\section{Fulvic acids (FS)}

The structure of the molecules and the physico-chemical properties of fulvic acids are similar to humic acids. Compared to humic acids, fulvic acids have a lower molecular weight, which is due to the lower content of aromatic structures and a greater number of aliphatic side chains. Their structure is more homogeneous. The difference is also in the elemental composition: fulvic acids contain a smaller percentage of carbon and a higher percentage of oxygen (because they contain more carboxyl and phenolic groups than the humic acid molecule). Thus, the percentage of elements is as follows: 46 - 55 wt. $\%$ of carbon, $37-50$ wt. $\%$ of oxygen, $4-5$ wt. $\%$ of hydrogen and a low nitrogen and sulphur content. Fulvic acids are characterized by light to light brown colour. They also exhibit better solubility in water. They are more dissociated, and therefore having a more acidic character $[1,4]$.

\section{MATERIALS AND METHODOLOGY OF EXPERIMENT}

The soil samples collection was carried out from the upper A genetic horizon to a depth of $30 \mathrm{~cm}$ at the following localities:

- Sample "Regozem Čenkov" (RMč) - forest steppe (meadow) near Mužla, Nové Zámky,

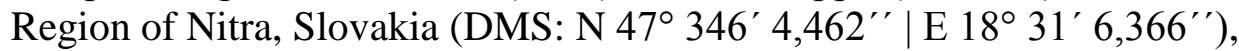

- Sample "Regozem Závod" (RMz) - agricultural cultivated field sampled near Závod, Malacky, Region of Záhorie, Slovakia (DMS: N 48 32' 44,786" | E $17^{\circ} 02^{\prime} 22,491^{\prime \prime}$ '),

- Sample "Smonica Gbely" (SM) - agricultural cultivated field near Gbely, Skalica, Region

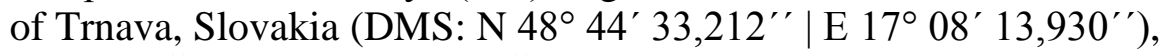

- Sample "Černozem Trnava" (ČM) cultivated soil at Botanical garden in Trnava. Botanická street, 91708 Trnava, Slovakia (DMS: N 4822' 25,364" | E $17^{\circ} 34^{\prime} 17,139^{\prime \prime}$ ).

Collected soil samples were placed in polythene bags. After transport to the laboratory, they were treated in a standard way, namely free drying in a dark and dry place, crushing in a porcelain mortar, homogenization and sieving to the size below $2 \mathrm{~mm}$. After that, all samples were characterised in detail by the methods reported in Fiala et al. [5]. Basic characteristics of the studied soils are:

- Sample "Regozem Čenkov" (RMč) - WRB: Calcearic Regosols; $\mathrm{pH}_{\text {wat. }}=7.33$ (weakly alkaline); $\mathrm{pH}_{\mathrm{KCl}}=7.19$ (neutral), clay $6.88 \%$, silt $9.48 \%$, sand 83.64 (sand); humus $1.17 \%$ (weakly humous),

- Sample "Regozem Závod" (RMz) - WRB: Eutric Regosols; $\mathrm{pH}_{\text {wat. }}=7.11$ (neutral); $\mathrm{pH}_{\mathrm{KCl}}=7.15$ (neutral), clay $6.80 \%$, silt $8.92 \%$, sand $6.80 \%$ (sand); humus $1.38 \%$ (weakly humous),

- Sample "Smonica Gbely" (SM) - WRB: Haplic Vertisols; $\mathrm{pH}_{\text {wat. }}=7.21$ (weakly alkaline); $\mathrm{pH}_{\mathrm{KCl}}=6.95$ (neutral), clay $30.80 \%$, silt $50.56 \%$, sand $18.64 \%$ (clayey soil); humus $4.72 \%$ (strongly humous),

- Sample "Černozem Trnava" (С̆M) - WRB: Haplic Chernozems; $\mathrm{pH}_{\text {wat. }}=7.60$ (weakly alkaline); $\mathrm{pH}_{\mathrm{KCl}}=6.89$ (neutral); clay $20.17 \%$, silt $53.50 \%$, sand $3.11 \%$ (silty soil); humus $2.36 \%$ (medium humous).

Simulation of fire was carried out in a laboratory oven/muffle furnace by exposing the samples of soil to the heat. The used temperatures were from $100{ }^{\circ} \mathrm{C}$ to $400{ }^{\circ} \mathrm{C}$ and constant for duration of 60 minutes. The samples were located on porcelain boats. They were filled up to 
approximately $0.5 \mathrm{~cm}$ with the exact weight of 10 grams. This was the standard procedure used in all our experiments and is complying e. g. with Badía and Martí [6] or Glass et al. [7].

After that, all samples were extracted, and their soil organic matter (SOM) was fractioned by the Konovova-Bel'ačkova method reported in Fiala et al. [5]. Briefly, the soil sample was extracted by sodium pyrophosphate solution and sodium hydroxide; the humic substances remained in the extraction solution. Humic acids were precipitated from the extract by acidification; the fulvic acids remained in solution.

The UV-VIS spectrophotometric determinations of SOM spectra were performed on the ThermoSpectronic Genesys ${ }^{\mathrm{TM}} 8$ spectrophotometer. The samples of humic substances and humic acids were applied to $1.0 \mathrm{~mm}$ and for fulvic acid $10.0 \mathrm{~mm}$ quartz cuvette (owing to low or high absorbances), and the resulting spectra were obtained by scanning their absorbances in the wavelength range $190-690 \mathrm{~nm}$ (resolution of recording $1 \mathrm{~nm}$ ). The spectra were recorded using the RS 232 Acces software, and evaluated using the MS Excel software.

\section{RESULTS AND DISCUSSION}

\section{Near ultraviolet and visible spectrum of humic substances}

Ultraviolet and Visible Molecular Absorption Spectrometry is the most common technique used in the study of humic substances which exhibit strong absorption in the wavelength range of $200-600 \mathrm{~nm}$. The absorbance of humic substances is influenced by the relative content of aromatic $-\mathrm{C}=\mathrm{C}-$ and ketonic $>\mathrm{C}=\mathrm{O}$ functional groups (chromophores) and auxochromes (e.g. $-\mathrm{OH}$ and $-\mathrm{NH}_{2}$ ). Auxochromes do not cause discolouration, but increase chromophore staining. Some chromophores and the corresponding transitions are shown in Table 1.

\begin{tabular}{|l|c|c|}
\hline \multicolumn{3}{|l|}{ Table 1 Chromophores and the corresponding transitions [8] } \\
\hline Chromophore (example of compound) & Transition & $\lambda$ max [nm] \\
\hline $\mathrm{H}_{2} \mathrm{O}$ & $\sigma \rightarrow \sigma^{*}$ & 183 \\
\hline $\mathrm{C}-\mathrm{C}$ and C-H, $\mathrm{CH}_{4}$ & $\sigma \rightarrow \sigma^{*}$ & $\sim 170,173$ \\
\hline $\mathrm{C}-\mathrm{X}, \mathrm{CH}_{3} \mathrm{OH}, \mathrm{CH}_{3} \mathrm{NH}_{2}, \mathrm{CH}_{3} \mathrm{I}$ & $\mathrm{n} \rightarrow \sigma^{*}$ & $180-260,187,215,258$ \\
\hline $\mathrm{C}=\mathrm{C}, \mathrm{H}_{2} \mathrm{C}=\mathrm{CH}_{2}$ & $\pi \rightarrow \pi^{*}$ & $160-190,162$ \\
\hline $\mathrm{H}_{2} \mathrm{C}=\mathrm{CH}-\mathrm{CH}=\mathrm{CH}_{2}$ & $\pi \rightarrow \pi^{*}$ & 217 \\
\hline$>\mathrm{C}=\mathrm{O}, \mathrm{H}-\mathrm{CH}=\mathrm{O}$ & $\mathrm{n} \rightarrow \pi^{*}, \pi \rightarrow \pi^{*}$ & $270,170-200,270,185$ \\
\hline $\mathrm{H}_{2} \mathrm{C}=\mathrm{CH}-\mathrm{CH}=\mathrm{O}$ & $\mathrm{n} \rightarrow \pi^{*}, \pi \rightarrow \pi^{*}$ & 328,208 \\
\hline $\mathrm{C}=\mathrm{N}$ & $\mathrm{n} \rightarrow \sigma^{*}, \mathrm{n} \rightarrow \pi^{*}$ & 190,300 \\
\hline $\mathrm{N}=\mathrm{N}$ & $\mathrm{n} \rightarrow \pi^{*}$ & 340 \\
\hline $\mathrm{C}=\mathrm{S}$ & $\mathrm{n} \rightarrow \pi^{*}$ & 500 \\
\hline $\mathrm{NO}_{2}$ & $\mathrm{n} \rightarrow \pi^{*}$ & $420-450$ \\
\hline $\mathrm{N}=\mathrm{O}$ & $\mathrm{n} \rightarrow \pi^{*}$ & $630-700$ \\
\hline
\end{tabular}

All humic substances studied show strong absorbantion between 190 - $240 \mathrm{~nm}$. As shown in Figure 1, the highest absorbance of humic substances extracted from non-heated $\left(20^{\circ} \mathrm{C}\right)$ soil RMč was recorded at $196 \mathrm{~nm}, \mathrm{RMz}$ at $195 \mathrm{~nm}, \mathrm{SM}$ at $197 \mathrm{~nm}$ and $\check{C} \mathrm{M}$ at $195 \mathrm{~nm}$. The absorbance at this region is mainly caused by thiols $-\mathrm{SH}(195 \mathrm{~nm})$, amines $-\mathrm{NH}_{2}(195 \mathrm{~nm})$ and ketones $>\mathrm{C}=\mathrm{O}(195 \mathrm{~nm})[9,10]$. 

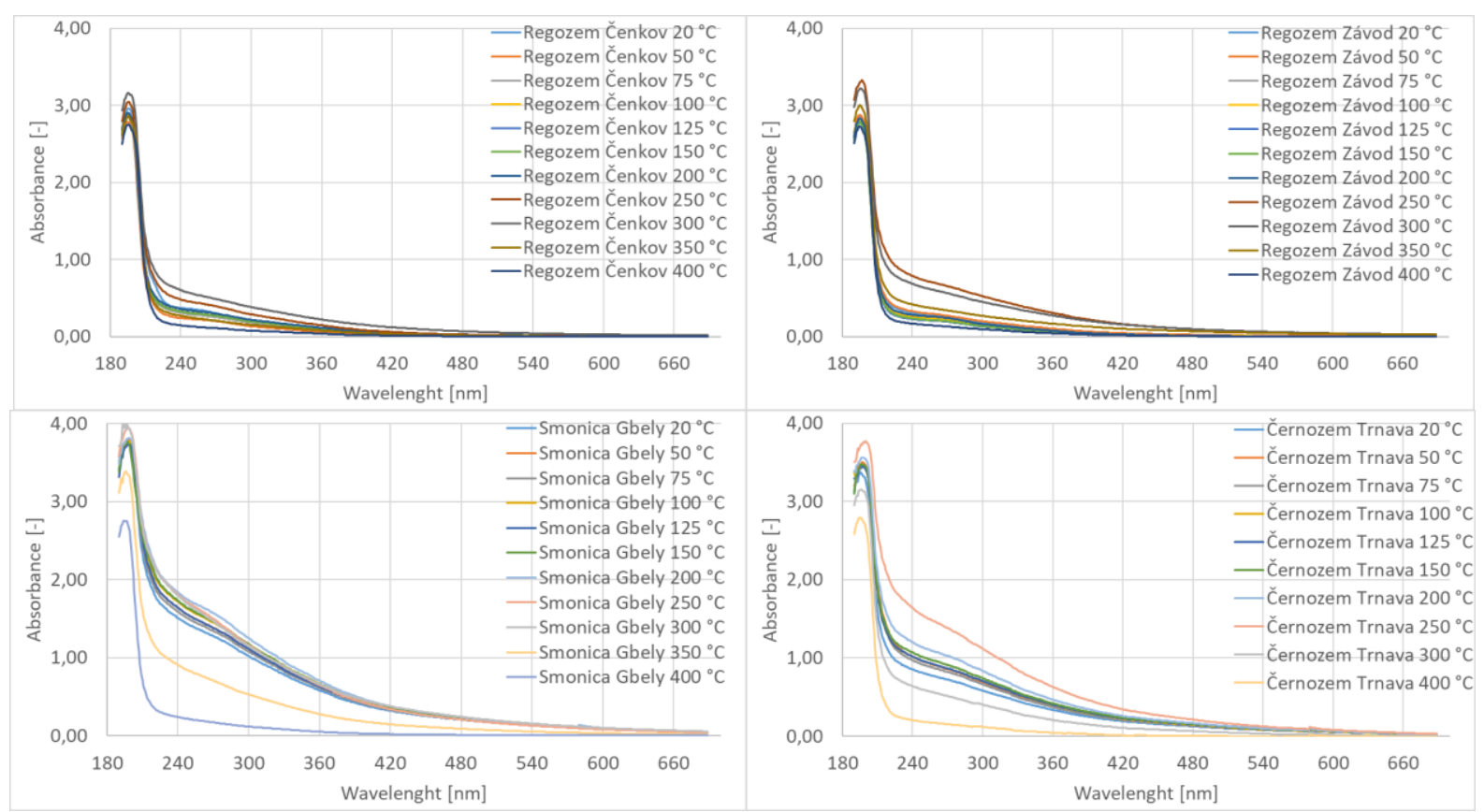

Figure 1 Absorption spectra of humic substances extracted from heating soils

The highest absorbance of humic acids (Figure 2) extracted from non-heated $\left(20^{\circ} \mathrm{C}\right)$ soil RMč was observed at $190 \mathrm{~nm}, \mathrm{RMz}$ at $191 \mathrm{~nm}, \mathrm{SM}$ at $190 \mathrm{~nm}$ and $\check{C} \mathrm{M}$ at $192 \mathrm{~nm}$. The absorbance at this region is mainly caused by oximes $-\mathrm{NOH}(190 \mathrm{~nm})$ and ethens $-\mathrm{C}=\mathrm{C}-$ $(190 \mathrm{~nm})[9,10]$.
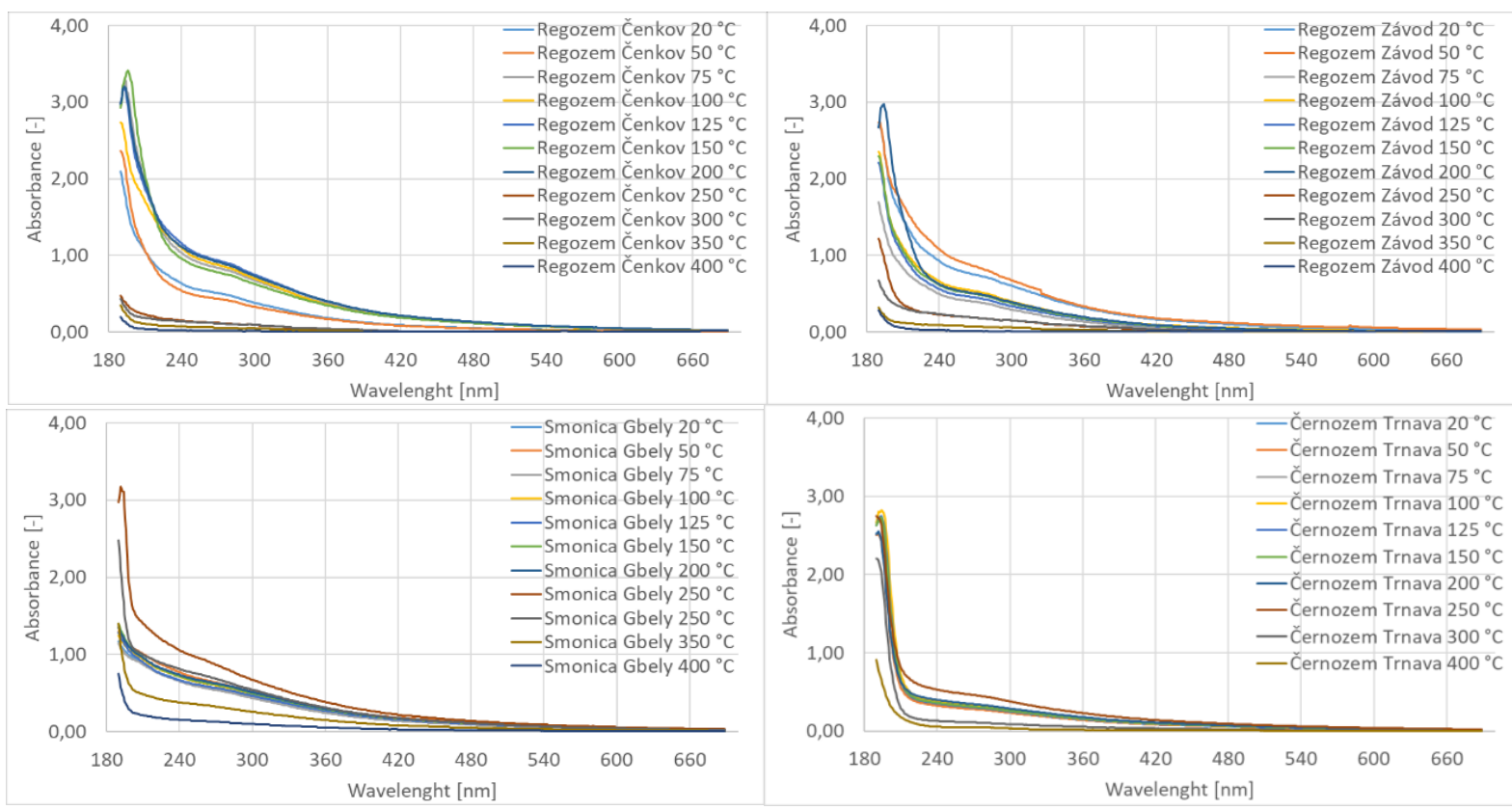

Fiure. 2 Adsorption spectra of humic acids extracted from heating soils

The highest absorbance of fulvic acids (Figure 3) extracted from non-heated $\left(20^{\circ} \mathrm{C}\right)$ soil RMč was recorded at $193 \mathrm{~nm}, \mathrm{RMz}$ at $194 \mathrm{~nm}, \mathrm{SM}$ at $195 \mathrm{~nm}$ and $\check{\mathrm{CM}}$ at $193 \mathrm{~nm}$. The absorbance at this region is mainly caused by thiols $-\mathrm{SH}(195 \mathrm{~nm})$, amines $-\mathrm{NH}_{2}(195 \mathrm{~nm})$ and ketones $>\mathrm{C}=\mathrm{O}(195 \mathrm{~nm})[9,10]$. 


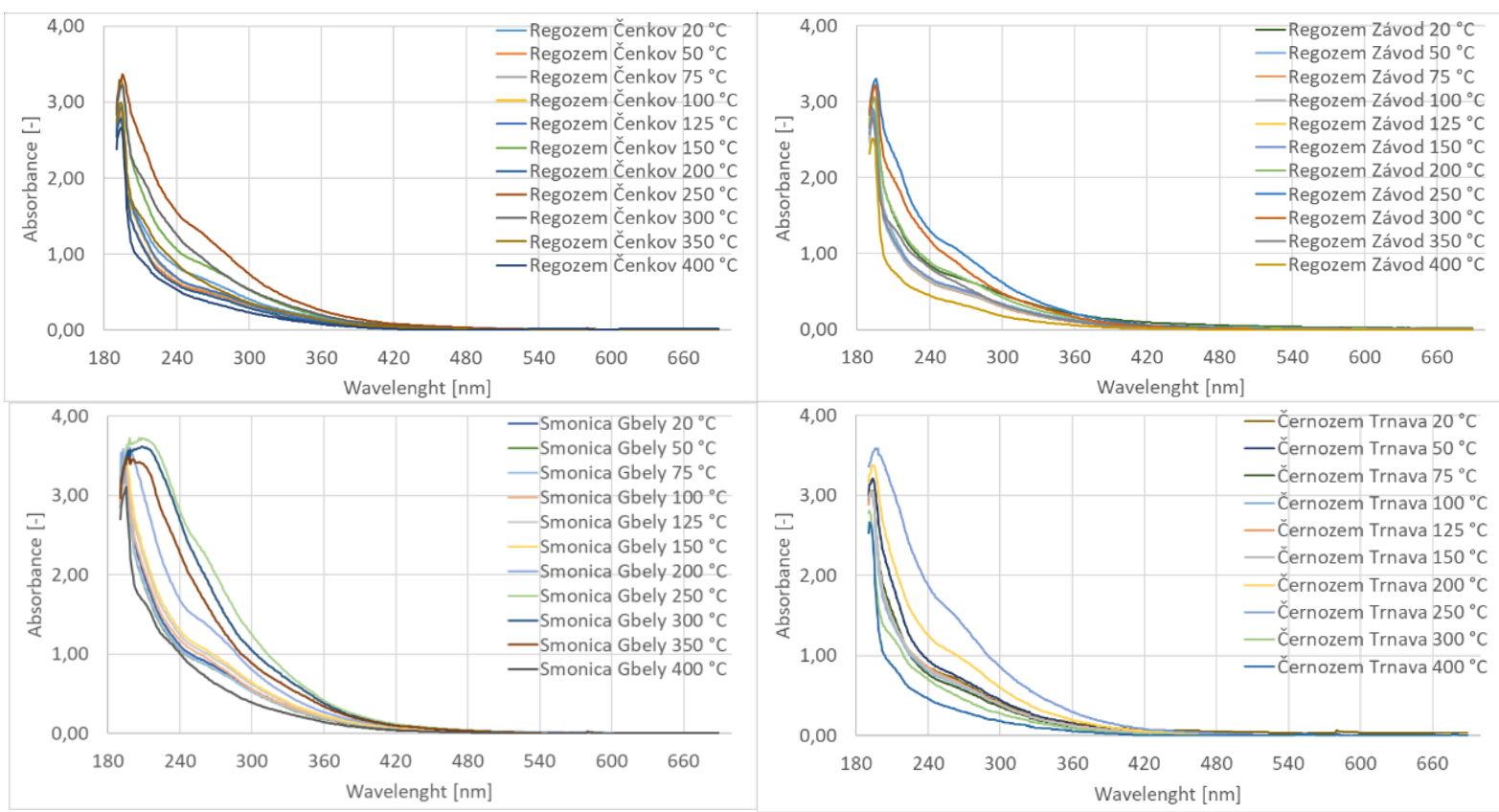

Figure 3 Absorption spectra of fulvic acids extracted from heating soils

The content of functional groups in humic substances can be derived from the intensity of radiation absorption at a given wavelength. For thermally altered soil samples, the absorbance of humic substances at $\mathbf{1 9 5} \mathbf{~ n m}$ is shown in Figures 4a, 4b, 4c. In the case of RMč and RMz, a slight decrease in absorbance occurs already at moderate heating, which is probably due to a decrease in the content of the thiol and amine groups by the breakdown of amino acids and labile proteins. A gradual increase in absorbance with increasing temperature (up to about $300{ }^{\circ} \mathrm{C}$ ) can probably be attributed to the increasing content of ketone functional groups. Above this temperature, there follows also their gradual destruction. The SM and ČM soil samples show a more stable SOM, with a slight increase in absorbance up to $300{ }^{\circ} \mathrm{C}$, and a later rapid loss of absorbance at further increasing temperatures.

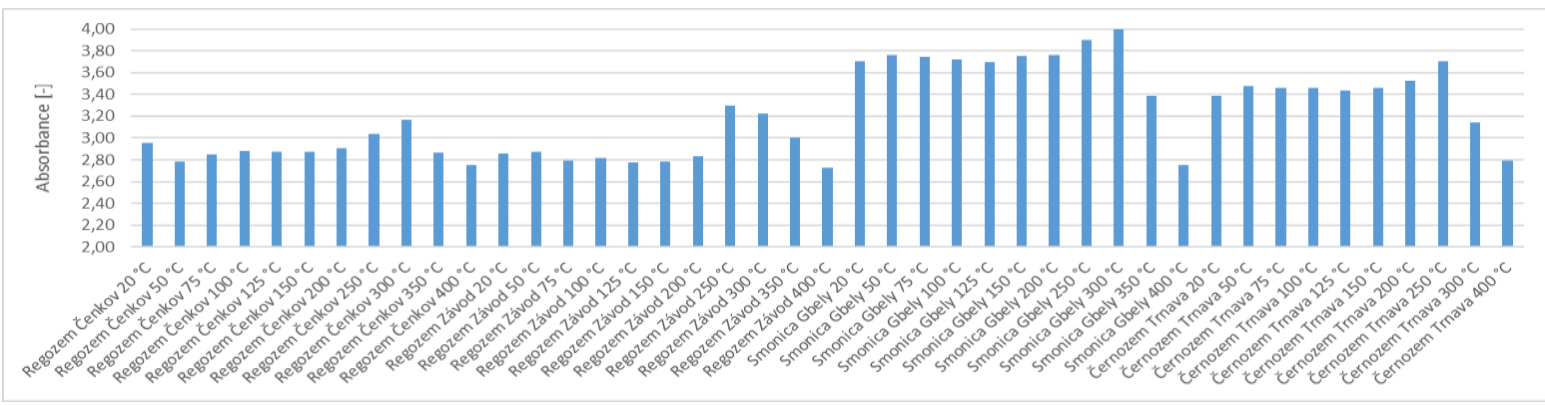

Figure 4a Absorbance of humic substances extracted from heated soils at $195 \mathrm{~nm}$

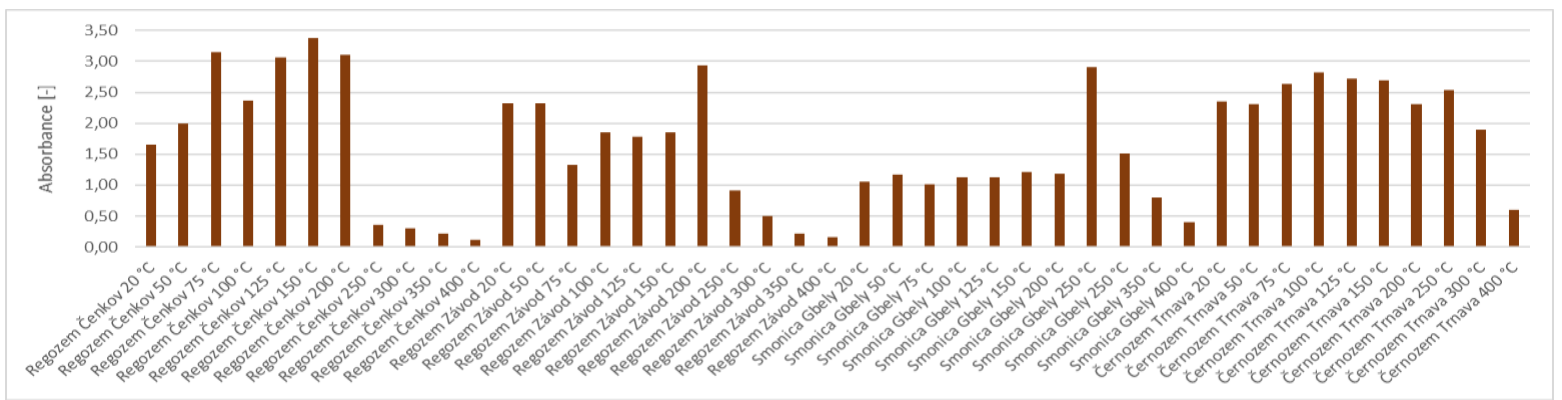

Figure $\mathbf{4 b}$ Absorbance of humic acids extracted from heated soils at $195 \mathrm{~nm}$ 


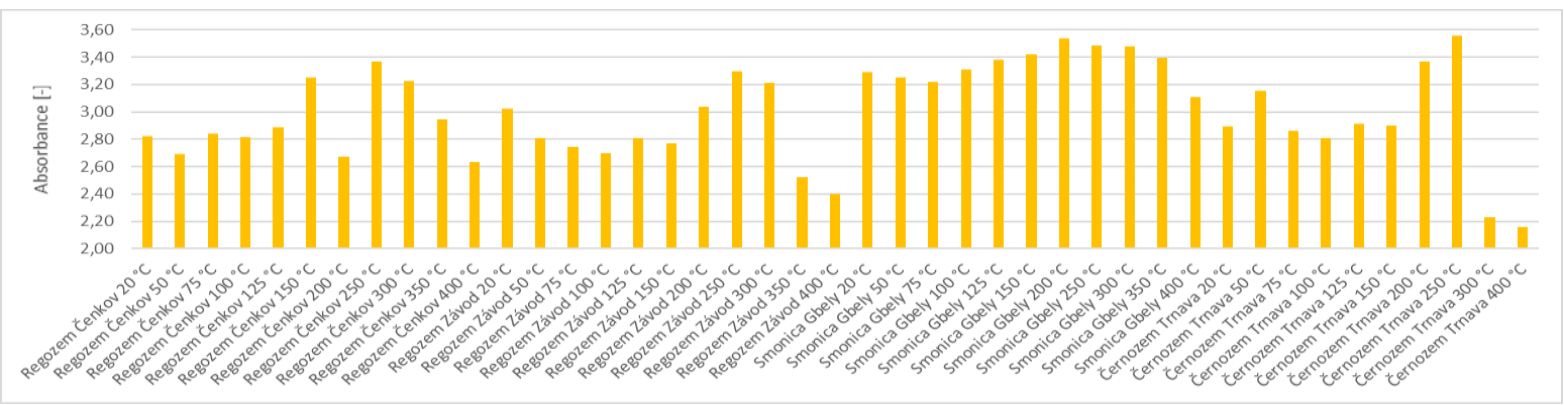

Figure 4c Absorbance of fulvic acids extracted from heated soils at $195 \mathrm{~nm}$

Less intense bands at 205 and $250 \mathbf{~ n m}$ are largely influenced by the presence of polar functional groups, such as e.g. hydroxyl, carbonyl and carboxyl, while the benzenoid band is almost unaffected. [11] Phillips [12] reports the absorption maxima at $\mathbf{2 0 5} \mathbf{~ n m}$ for esters, carboxyl, and $\mathbf{2 1 0} \mathbf{~ n m}$ for aldehyde, sulphoxides and nitro- groups. With increasing temperature, the content of these functional groups in the tested soils was essentially analogous to the previous case. It is possible to observe their greater variability in the ČM soil humic substances.

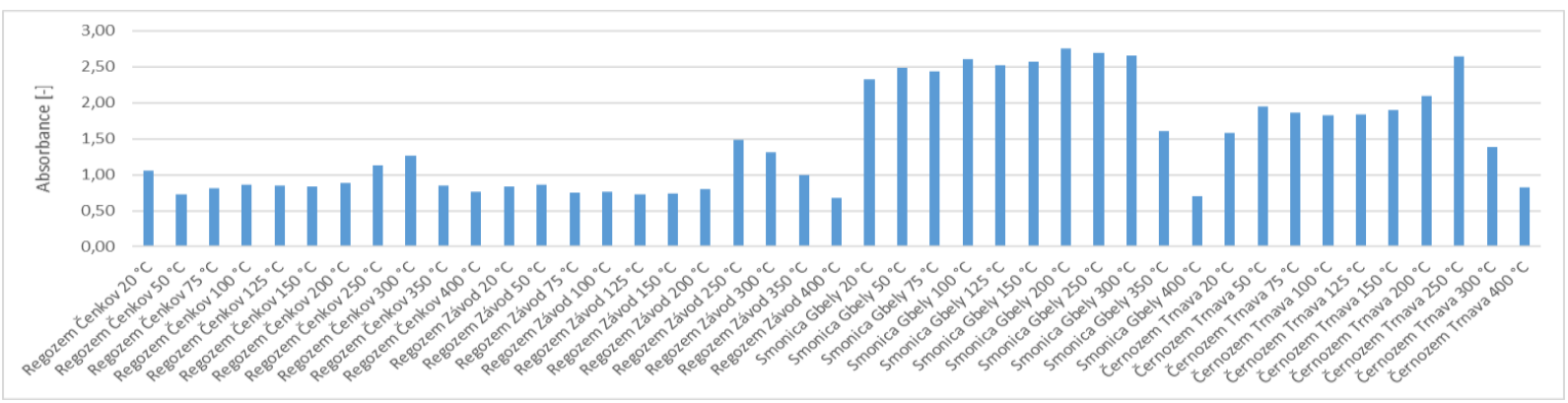

Figure 5a Absorbance of humic substances extracted from heated soils at $210 \mathrm{~nm}$

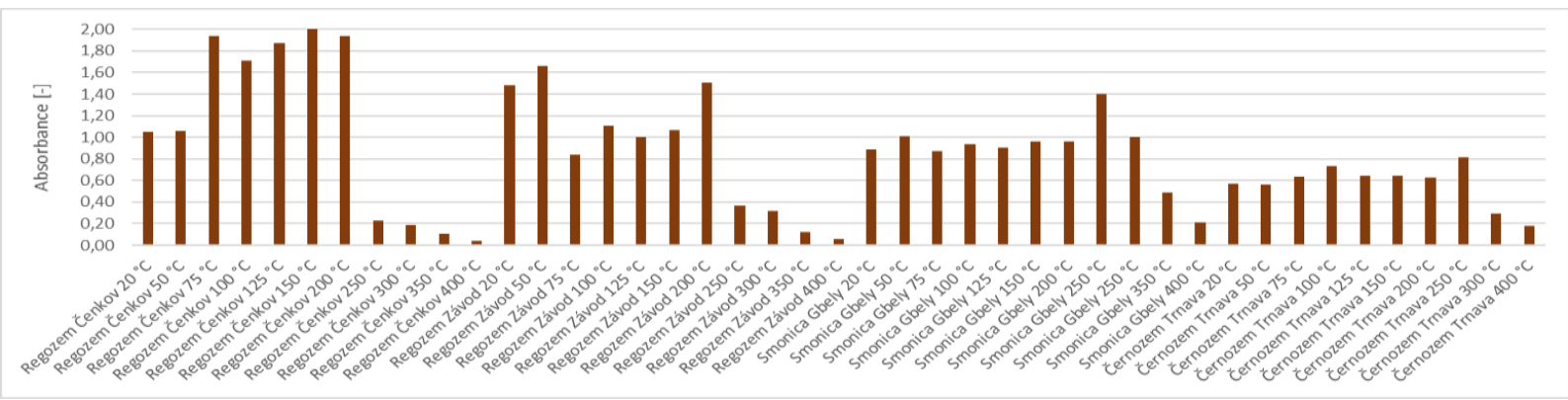

Figure $5 \boldsymbol{b}$ Absorbance of humic acids extracted from heated soils at $210 \mathrm{~nm}$

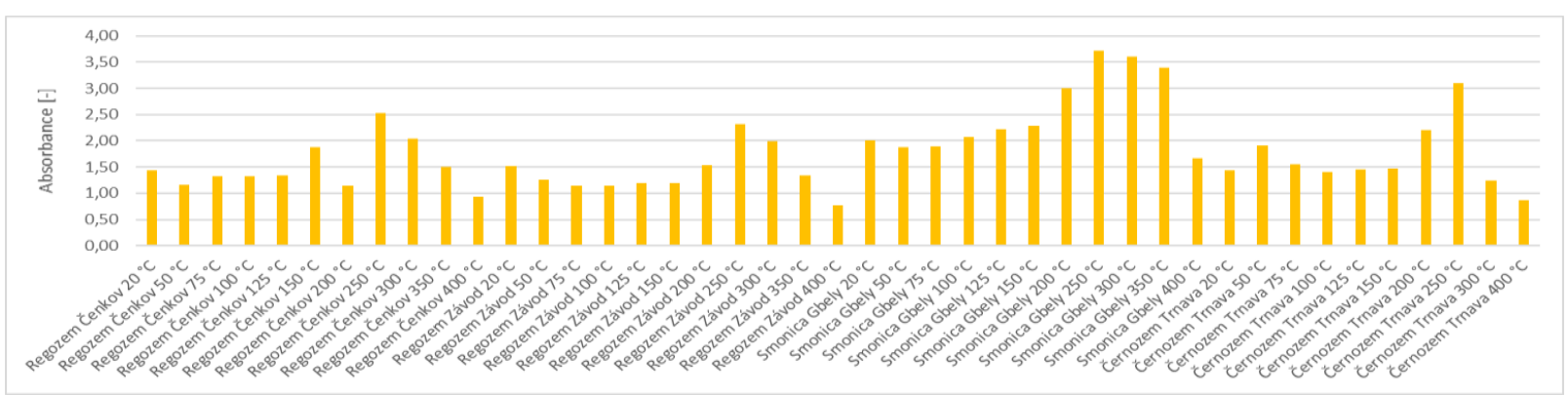

Figure 5c Absorbance of fulvic acids extracted from heated soils at $210 \mathrm{~nm}$ 
The absorbance below $\mathbf{2 6 0} \mathbf{~ n m}$ is used to compare the relative aromatic content of $-\mathrm{C}=\mathrm{C}-$ (substituted benzenes and polyphenols exhibit increased absorbance in this region). UV absorbance at $260-\mathbf{2 8 0} \mathbf{~ n m}$ is due to lignin and quinone structures (material at the very beginning of transformation). [13] Also, the absorbance at $280 \mathbf{~ n m}$ represents the total aromaticity, since the $\pi-\pi^{*}$ electron transition occurs in this region of ultraviolet radiation (about $270-280 \mathrm{~nm}$ ). It includes phenolic arenes, benzoic acids, aniline derivatives, polyenes and polycyclic aromatic hydrocarbons having two or more rings. The ketone functional group exhibits poor absorbance in the visible spectrum, and is virtually zero at the wavelengths $>350$ $\mathrm{nm}$ [13]. As can be seen in Figures 6a, 6b, 6c, the amount of these substances increases slightly to a temperature of about $250-300{ }^{\circ} \mathrm{C}$ followed by a sudden sharp decrease.

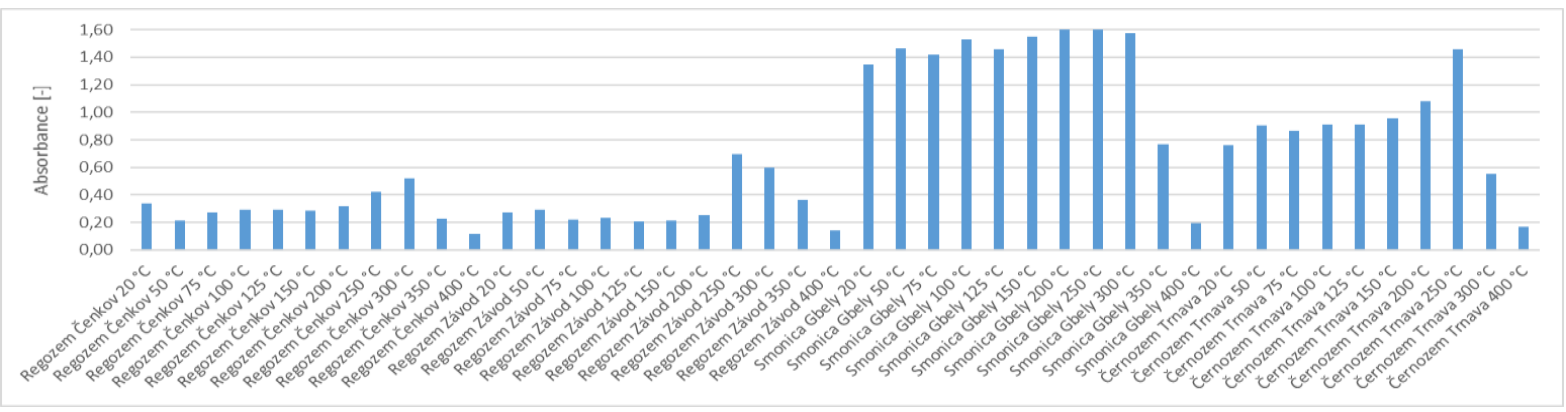

Figure 6a Absorbance of humic substances extracted from heated soils at $260 \mathrm{~nm}$

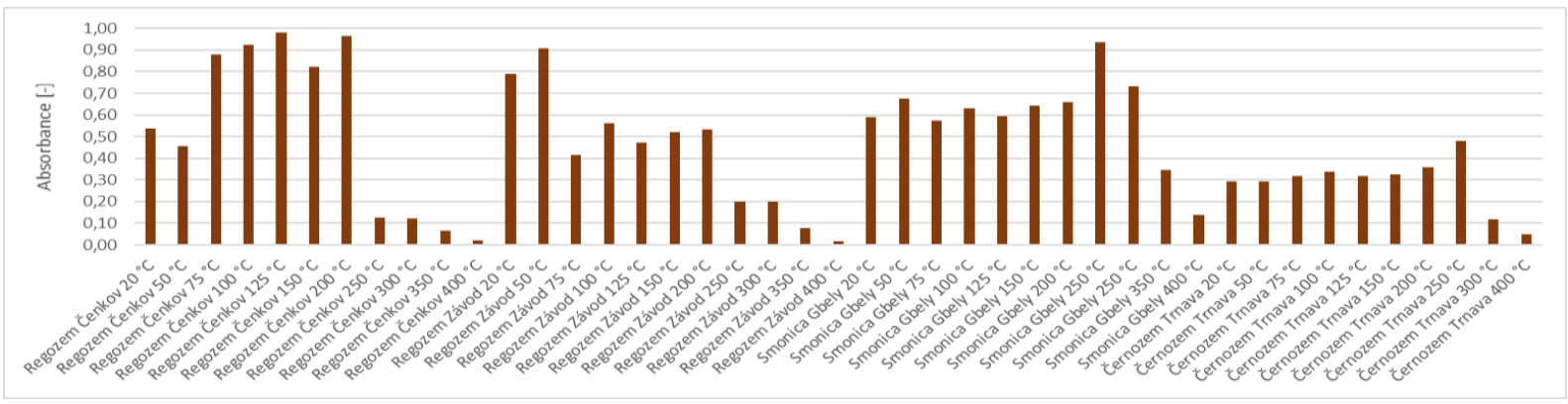

Figure $\mathbf{6 b}$ Absorbance of humic acids extracted from heated soils at $260 \mathrm{~nm}$

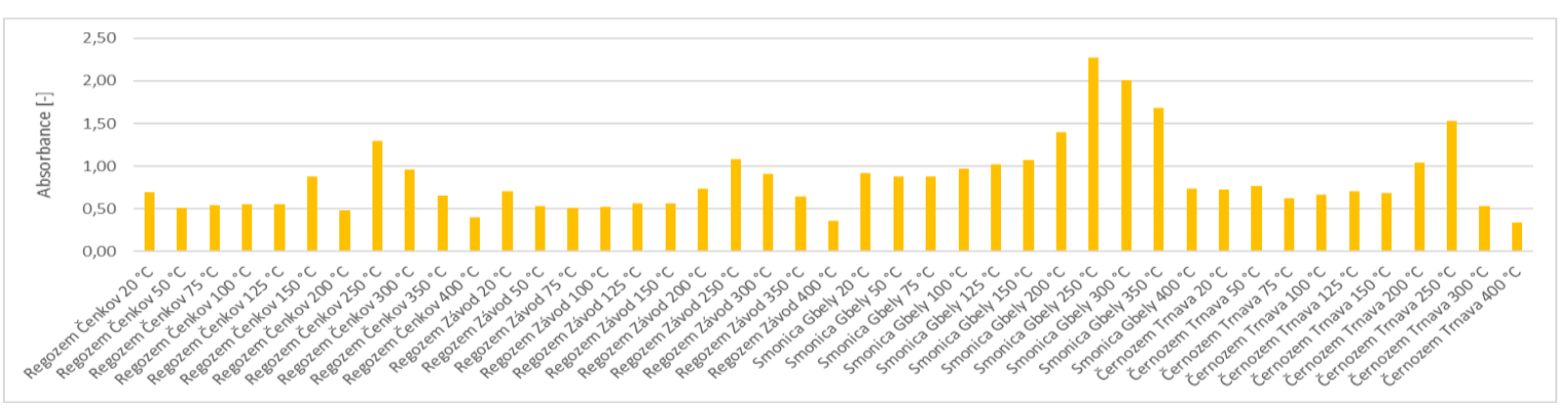

Figure 6c Absorbance of fulvic acids extracted from heated soils at $260 \mathrm{~nm}$

The absorbance at $\mathbf{4 6 0}-\mathbf{4 8 0} \mathbf{n m}$ characterizes the organic material at the beginning of humification [13]. As can be seen from Figures 7a, 7b, 7c the stocks of non-humic substances in sandy soils are very low, while it is much higher in clayey and silty soils. With increasing temperature, their conversion accelerates, preferably during the formation of humic then fulvic acids. 


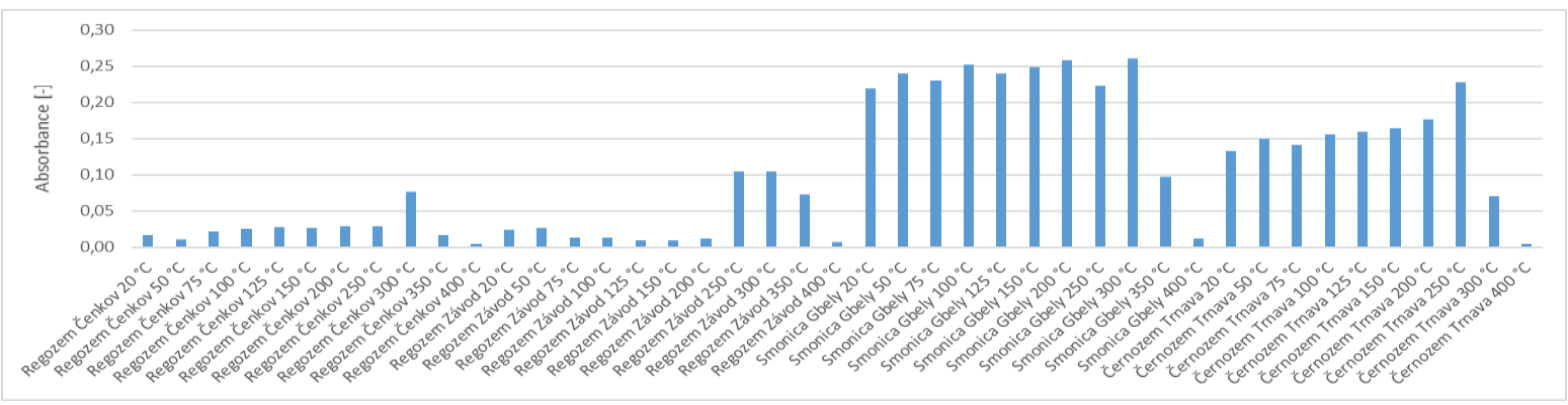

Figure 7a Absorbance of humic substances extracted from heated soils at $470 \mathrm{~nm}$

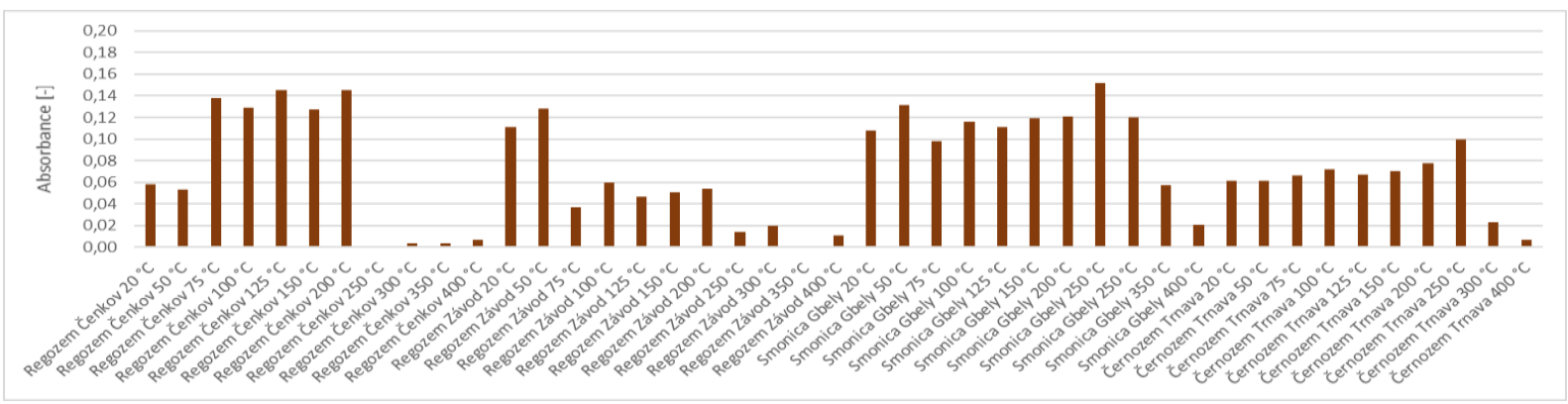

Figure $7 \boldsymbol{b}$ Absorbance of humic acids extracted from heated soils at $470 \mathrm{~nm}$

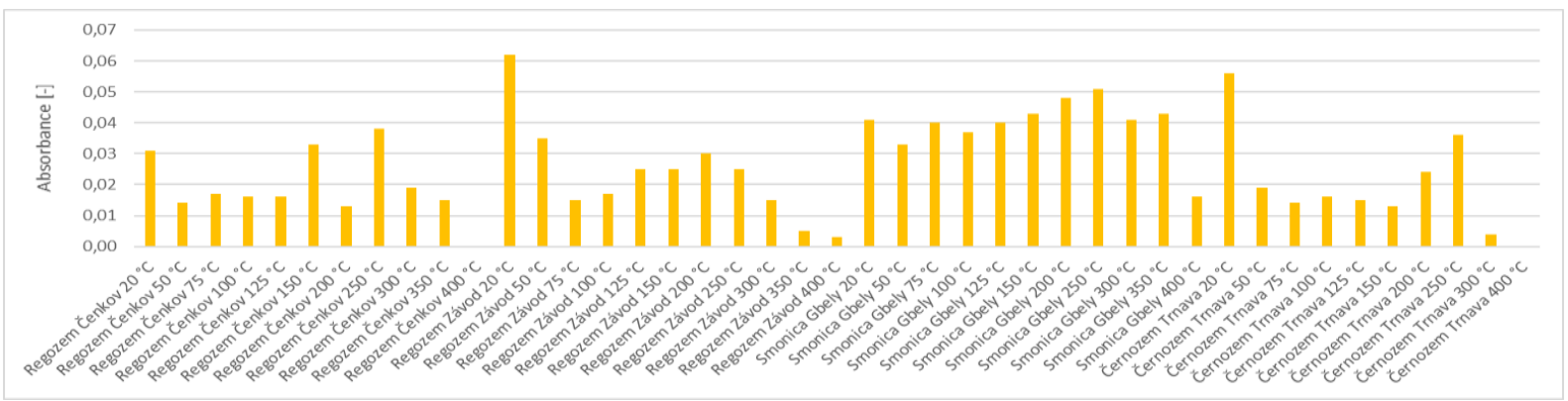

Figure 7c Absorbance of fulvic acids extracted from heated soils at $470 \mathrm{~nm}$

The absorbance at $\mathbf{6 0 0}-\mathbf{6 7 0} \mathbf{~ n m}$ is evidence of a highly humified material with a high degree of aromatic, condensed groups [13]. As can be seen from Figures 8a, 8b, 8c, with increasing temperature, the content of humic substances increases to a temperature of approximately 250 resp. $300{ }^{\circ} \mathrm{C}$. Then they are degraded.

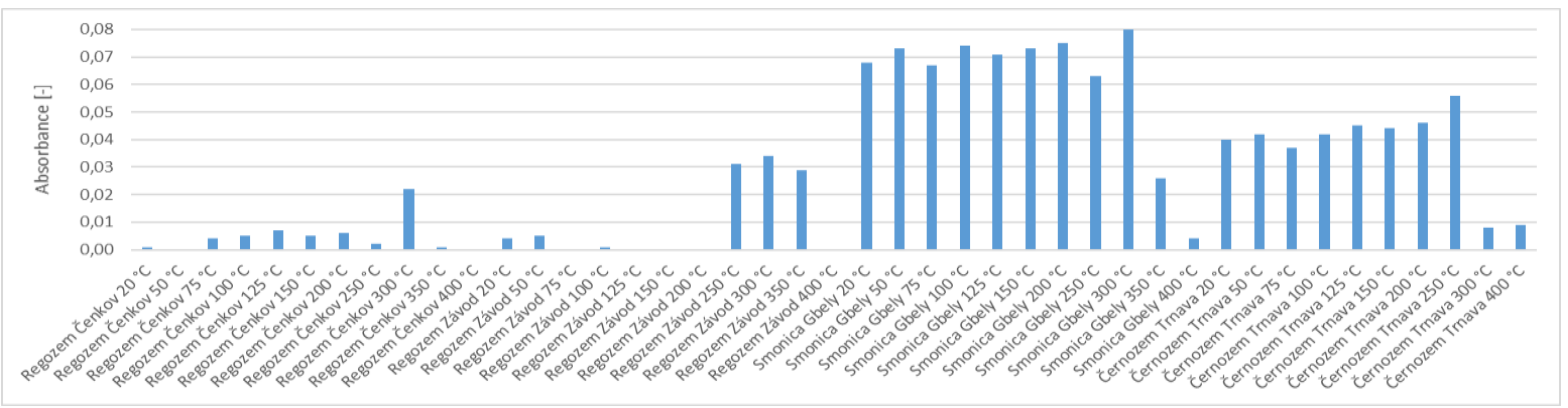

Figure 8a Absorbance of humic substances extracted from heated soils at $635 \mathrm{~nm}$ 


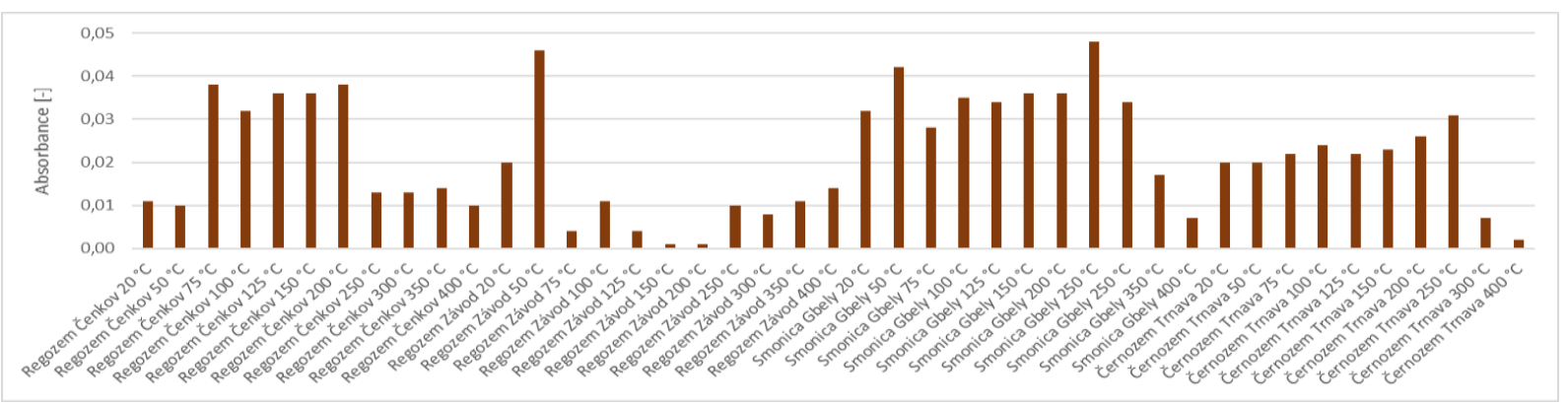

Figure $8 \boldsymbol{b}$ Absorbance of humic acids extracted from heated soils at $635 \mathrm{~nm}$

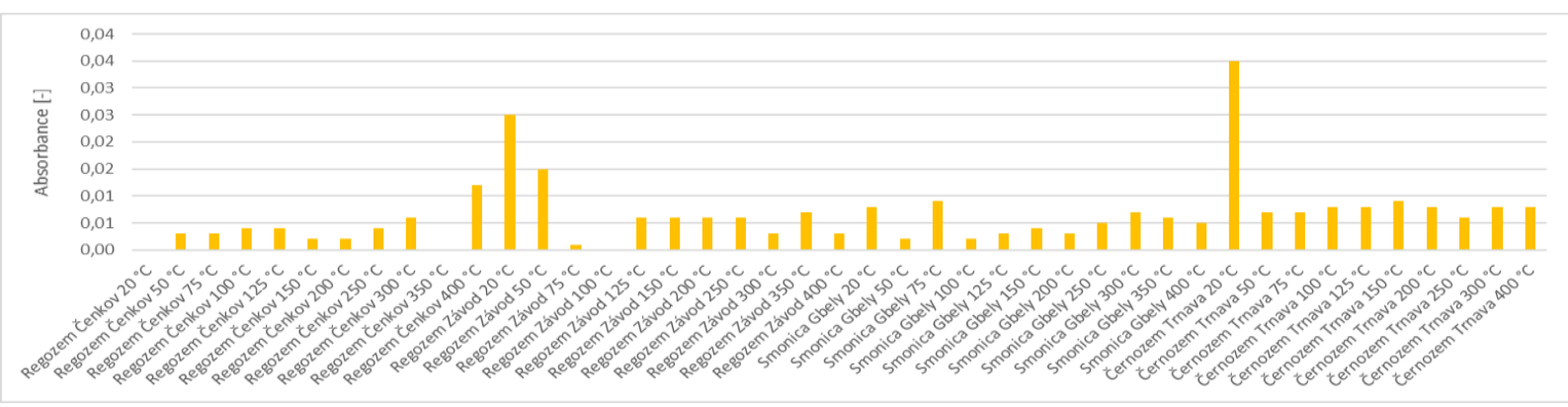

Figure 8c Absorbance of fulvic acids extracted from heated soils at $635 \mathrm{~nm}$

The UV-VIS spectral analysises can indicate organic carbon content, aromatic content, double bonds, molecular size, and chromophoric groups; predict lignin phenols/hydrophobic fractions; and monitor organic pollutants removal. For further interpretation of the UV-VIS spectra, often used are e.g. diagnostic ratios of absorbances at the selected wavelengths or spectral slope, which will be the subject of the next article. The most widely used are:

- Absorption ratios, such as $\mathrm{E}_{2} / \mathrm{E}_{3}$ (at $250 / 365 \mathrm{~nm}$ ), $\mathrm{E}_{2} / \mathrm{E}_{4}$ (at $265 / 465 \mathrm{~nm}$ ), and $\mathrm{E}_{4} / \mathrm{E}_{6}$ (at $465 / 665 \mathrm{~nm}$ ), are frequently used to monitor the changes of molecular weight, aromaticity, polarity, humification, and hydrophobicity of natural organic matter $[14,15,16]$.

- Spectral slope, such as $\mathrm{S}_{275-295}, \mathrm{~S}_{275-295} / \mathrm{S}_{350-400}$, DSlope $240-280$, DSlope $325-375$, etc. can track the changes of MW, metal binding affinity, and functional groups; indicate natural organic matter sources, etc. $[17,18]$.

- Gaussian decomposition method is based on the allocation of Gaussian bands through numerical deconvolution of UV-VIS spectra. This method can be used to track the changes of molecular structure in natural organic matter under various external stimulations [19].

- 2DCOS analysis is a mathematic algorithm to enhance the spectral resolution by spreading the spectra along the second dimension, and more importantly discern relative directions and specific orders of spectral changes upon a specific external perturbation, such as $\mathrm{pH}$, time, temperature, and ion strength [19].

\section{CONCLUSION}

Exposure of soil organic matter to elevated temperatures, such as natural fires, means a significant impact on its quality and quantity. For a quick insight into the issue of changes in the soil organic matter caused by heat, it is possible to use either the UV-VIS spectrophotometry method, i.e. recording the entire absorbed spectrum of extracted humic substances, or specific diagnostic absorbance ratios. The results indicate gradual changes in the composition of the soil 
organic matter with increasing temperature in the range of $20-300{ }^{\circ} \mathrm{C}$. Above this temperature, it mineralizes, which is reflected in a sharp decrease in absorbances.

\section{Acknowledgements}

This work was supported by the Slovak Research and Development Agency under the contract No. APVV-16-0223.

\section{References}

[1] ČURLÍK, J., JURKOVIČ, L. 2012. Pedogeochemistry, Comenius University in Bratislava. 227 p. ISBN: 978-80-223-3210-1

[2] LIU, S., BENEDETTI, M.F, HAN, W, KORSHIN, G .W. 2020. Comparison of the properties of standard soil and aquatic fulvic and humic acids based on the data of differential absorbance and fluorescence spectroscopy. Chemosphere, 261, 128189.

[3] SKOKANOVÁ, M., DERCOVÁ, K. 2008. Humic acids. Interaction of humic acids with contaminants. Chemical letters. 102. 338-345.

[4] STEVENSON, F. J. 1994. Humus chemistry: Genesis, composition, reactions. 2nd edition. New York, p. 496. ISBN 0-471-59474-1.

[5] FIALA, K. et al. 1999. Mandatory methods of soils analysis. Bratislava: VÚPOP Bratislava, 142 p. ISBN 80-85361-55-8

[6] BADÍA, D. and MARTÍ, C. 2003. Plant ash and heat intensity effects on chemical and physical properties of two contrasting soils. Arid Land Research and Management, 17, pp. 23-41.

[7] GLASS, D.W., JOHNSON, D.W., BLANK, R.R. and MILLER, W.W. 2008. Factors affecting mineral nitrogen transformation by soil heating: a laboratory - simulated fire study. Soil Science, 173,6 , pp. $387-400$.

[8] POUSTKA, J. 2021. Ultraviolet and visible spectrometry. Advanced strategies in food analysis. [Online]. [Accessed: 02-2021] Available at: https://web.vscht.cz/ poustkaj/SFA-9UV_VIS_spectrometry.pdf

[9] PERKAMPUS, H.H. 1992. UV-VIS atlas of organic compounds. Part 1. Spectra A1/1 - C9/13. 2nd ed. Weinheim: VCH Publishers. 336 p. ISBN 3527285105.

[10] PERKAMPUS, H.H. 1992. UV-VIS atlas of organic compounds. Part 2. Spectra D1/1 - M19. 2nd ed. Weinheim: VCH Publishers. pp. 336 - 1525. ISBN 3527285105.

[11] CHIN, Y.P., AIKEN, G. and O'LOUGHLIN, E. 1994. Molecular Weight, Polydispersity, and spectroscopic Properties of Aquatic Humic Substances. Environ. Sci. Technol., 28, 11, pp. 18531858

[12] PHILIPS, G. F. 2019. Chemistry: Molecular Spectroscopy - UV-VIS Spectroscopy. Kaye and Lal Table of Physical and Chemical Constants [Online]. [Accessed: 04-2019] Available at: http://www.kayelaby.npl.co.uk/chemistry/3_8/3_8_7.html

[13] ALBRECHT, R., PETIT, J.L., TERROM, G. and PÉRISSOL, C. 2011. Comparison between UV spectroscopy and NIRs to assess humification process during sewage sludge and green wastes cocomposting. Bioresource Technology, 102, 6, pp. $4495-4500$.

[14] FREY, K.E., SOBCZAK, W.V., MANN, P.J. and HOLMES, R.M. 2016. Optical properties and bioavailability of dissolved organic matter along a flow-path continuum from soil pore waters to the Kolyma River mainstem, East Siberia. Biogeosciences, 13, 8, pp. 2279 - 2290.

[15] LI, P.H., HUR, J. 2017. Utilization of UV-Vis spectroscopy and related data analyses for dissolved organic matter (DOM) studies: A review. Critic. Rev. Environ. Sci. Tech., 47, 3, pp. $131-154$.

[16] MACHADO, W., FRANCHINI, J.C., de FÁTIMA GUIMARÃES, M. and FILHO, J.T. 2020. Spectroscopic characterization of humic and fulvic acids in soil aggregates, Brazil. Heliyon, 6, 6, e04078.

[17] RODRÍGUEZ, F.J., SCHLENGER, P. and GARCÍA-VALVERDE, M. 2016. Monitoring changes in the structure and properties of humic substances following ozonation using UV-Vis, FTIR and ${ }^{1}$ H NMR techniques. Sci. Total Environ. 541, pp. $623-637$.

[18] HELMS, J., STUBBINS, A., RITCHIE, J., MINOR, E., KIEBER, D. and MOPPER, K. 2007. Absorption Spectral Slopes and Slope Ratios as Indicators of Molecular Weight, Source, and 
Photobleaching of Chromophoric Dissolved Organic Matter. Limnology and Oceanography. 53, pp. 955 - 969.

[19] CHEN, W. and YU, H.Q. 2021. Advances in the characterization and monitoring of natural organic matter using spectroscopic approaches. Wat. Res., 190, 116759.

\section{ORCID}

Maroš Sirotiak 0000-0003-1487-801X

Alica Pastierová $\quad$ 0000-0003-1442-9652

Lenka Blinová 0000-0001-6971-6558 